Chemistry and Physics of Lipids 17 (1976) 301-314

○ North-Holland Publishing Company

\title{
A SHIFT FROM PHOSPHOLIPID TO TRIGLYCERIDE SYNTHESIS WHEN CELL DIVISION IS INHIBITED BY TRANS-FATTY ACIDS
}

\author{
Gustáv GRAFF and William E.M. LANDS \\ Department of Biological Chemistry, The University of Michigan, Ann Arbor, MI 48109, USA
}

The yeast mutant Saccharomyces cerevisiae (KD 46) requires added unsaturated fatty acid for growth. When cell growth was inhibited by the presence of trans-acids there was a marked inhibition of oleate esterification into phospholipids accompanying continued incorporation into triglycerides. Apparently some control point in phospholipid synthesis associated with the cell cycle occurs after the stage of phosphatidate biosynthesis.

\section{Introduction}

The significance of phospholipids in supporting vital functions of living cells has been attested to by many investigators. An historic illustration is the comment of Thudichum [1]:

"Phosphatides are the center, life, and chemical soul of all bioplasm whatsoever, that of plants as well as animals. Their chemical stability is greatly due to the fact that their fundamental radicle is a mineral acid of strong and manifold dynamicities. Their varied functions are the result of the collusion of radicles of strongly contrasting properties. Their physical properties are, viewed from a teleological point of standing, eminently adapted to their functions."

Glycerophospholipids normally occur in cell membranes not as pure compounds, but as mixtures of many different individual molecular species. The recognized variety of permutations of acyl chains and polar head groups in the naturally occurring mixtures made the extensive synthetic experiments of Erich Baer, a needed and welcome contribution to our knowledge of these compounds (summarized in ref. [2]). His synthetic compounds made it possible to obtain the first reliable data on the physical and chemical properties of individual phospholipids, and they were also the first pure, individual phospholipids available for biological research. He developed methods for the synthesis of some of Nature's most intriguing biological compounds whose significance to life processes has become the subject of intensive research.

Our laboratory has recently begun to examine in more detail the manner by which the different fatty acyl chains can influence cell physiology. In a S. cerevisiae mutant which cannot synthesize unsaturated acids, and thus requires an exogenous supply, we noted that the ability of the culture to sustain its growth was related to the amount of the vital acyl chain in the phospholipids [3]. The contribution of the 
different acyl chains within the phosphoglycerides to cell function appeared to be linearly additive in simple cases, and cell division was attainable only above certain threshold concentrations [3]. Thus, our results serve to reaffirm the concept of a vital role for phospholipids in cell functions.

When the cells were challenged with mixtures of cis- $^{2}$ and trans-octadecenoic acids, we found a marked inhibition of growth was caused by specific trans-positional isomers [4]. Furthermore, the inhibited cultures at stationary phase tended to have slightly greater phospholipid contents per cell, but very much greater levels of neutral lipid per cell. The experiments in the following report were designed to examine the manner by which these changes occurred. The results indicate an impairment of phospholipid synthesis is associated with the impairment of growth.

\section{Methods and materials}

\section{A. Reagents}

Yeast extract, Bacto-agar, and Bacto-peptone were obtained from Difco Co., dextrose, reagent grade, was a product of Matheson, Coleman and Bell. Tween-80 was obtained from Fisher Scientific Co., Tween-40, 2,5-diphenyloxazole (PPO) and Triton X-100 were obtained from Sigma Chemical Co. p-bis[2-(5-phenyloxazolyl)] benzene (POPOP) was a product from New England Nuclear. Other reagents used, reagent grade, were obtained from either Mallinckrodt Chemical, Baker Analyzed Reagents or Fisher Scientific Conpany. Boron trifluoride in methanol was obtained from Applied Science Laboratories.

\section{B. Fatty acids}

The 9-cis- (oleic acid), 9-trans-(elaidic acid) and 11-trans-octadecenoic acids (trans-vaccenic acid) were obtained from either the Hormel Institute or the NuchekPrep Laboratory in the highest purity obtainable. $9-10 \cdot\left[{ }^{3} \mathrm{H}\right]$-cis-Octadecenoic acid $(2.5 \mathrm{Ci} / \mathrm{mmol})$ was purchased from Amersham. $\left[1{ }^{14} \mathrm{C}\right] 9$-trans-octadecenoic acid ( $55.7 \mathrm{mCi} / \mathrm{mmol}$ ) was obtained from Applied Science Laboratories.

Solutions of the fatty acid ammonium salt $(10-20 \mathrm{mM})$ were prepared as follows: to a weighed quantity of free fatty acid, a few drops of $\mathrm{NH}_{4} \mathrm{OH}$ were added, the tube was thoroughly mixed, the excess ammonia evaporated in a stream of nitrogen, and the ammonium soaps dissolved in absolute ethanol. Quantitation of the concentration was performed by gas liquid chromatography after esterification with $\mathrm{BF}_{3}$ in methanol [5] in the presence of a known quantity of pentadecanoic acld. Specific activities of $0.5-1.0 \times 10^{3} \mathrm{cpm} / \mathrm{nmol}$ of fatty acid were employed in experiments on the uptake and esterification of radioisotope-labeled fatty acids into cell lipids.

The purity of the radioactive acid was frequently checked by thin layer chromatography on silica gel $\mathbf{H}$, developing with the following solvent system. petroleum 
ether: diethyl ether : acetic acid $(40 / 60 / 1)(v / v / v)$. Only preparations containing more than $95 \%$ of the isotope in the free fatty acid region were employed.

\section{Measurement of radioactivity}

The liquid scintillation fluid contained $200 \mathrm{ml}$ Triton $X-100,800 \mathrm{ml}$ toluene, $4 \mathrm{~g}$ 2,5-diphenyloxazole (PPO) and $50 \mathrm{mg}$ p-bis [2-(5-phenyloxazolyl)]-benzene (POPOP). Aqueous sainples $(0.5 \mathrm{ml})$ were counted in $10 \mathrm{ml}$ of the scintillation fluid without additional water; lipids and silica gel samples were counted in fluid that contained an addition of $5 \%$ water. Quenching was determined by addition of an internal standard to samples, and quench corrections, to evaluate overall isotope recovery, were always employed. Liquid scintillation counting was performed in an ambient temperature Packard, Model 2002 Tricarb, liquid scintillation counter. Settings of 50-200 and 150-1000, at 50 and 20\% gain were employed for tritium and carbon14 , respectively. Under these conditions approximately $10 \%$ of carbon- 14 activity appeared in the tritium channel, and $5 \%$ of tritium in the carbon-14 channel. Corrections for isotope crossover were made with the aid of a Hewlett Packard Model 9810A programable calculator. Calculations of the exient of incorporation of labeled fatty acids into cell lipids were based on the specific activity of the substrate added to the culture medium.

\section{Organisms and media}

The mutant used throughout this study (Saccharomyces cerevisiae KD46 (ole 2)) was a generous gift of Dr. Alec Keith, Department of Biophysics, Pennsylvania State University. It is deficient in the ability to desaturate saturated fatty acids and required exogenous unsaturated fatty acid. Yeast cultures were grown in the basal medium consisting of $1 \%$ yeast extract, $2 \%$ Bacto-peptone and $2 \%$ dextrose (YEPD), as described by Keith et al. [6]. The mutant was kept free of revertants and other contaminants by weekly transfers to agar plates containing Tween-80 (1\%) (v/v), and replica plating onto Tween-80 and Tween-40 (0.2\% v/v) plates.

\section{E. Growth measurements}

Validated cell clones of KD 46 were transferred from agar plates into liquid medium containing $60 \mu \mathrm{M}$ ammonium oleate and grown for 16 hours (to mid or late log phase). The cells were separated by centrifugation, washed and resuspended in fresh medium. Aliquots were transferred into experinental tubes $(10.0$ to $16.0 \mathrm{ml})$ giving an initial cell density of about 5 to 10 million cells per ml. Generally, $50 \%$ of the cells in such inoculations were capable of forming colonies. To obtain a more viable inoculum, cell clones from plates were grown in $75 \mu \mathrm{M}$ oleic acid for $12 \mathrm{hr}$ (mid log phase), isolated, washed with fresh medium and resuspended in a minimum of fresh medium. Aliquots were transferred into fresh cultures containing $50 \mu \mathrm{M}$ oleic acid to 
give an initial cell density of about 5 million cells $/ \mathrm{ml}$ and grown for another $12 \mathrm{hr}$. The cells were centrifuged, washed as described above, and used to inoculate the experimental cultures. With this method the viable cell populations ranged between 70 and $100 \%$.

The experimental growth cultures were shaken at $30^{\circ} \mathrm{C}$ at $280 \mathrm{rpm}$ on a rotary shaker in tubes $(18 \times 150 \mathrm{~mm})$ set at an angle of $50^{\circ}$. At various times during growth the cell densities were determined turbidometrically by reading the absorbancies at $660 \mathrm{~nm}$ in a Bausch and Lomb Spectronic 20. Conversion of optical densities $\left(A_{660}\right)$ into cells $/ \mathrm{ml}$ was achieved by a computer-fitted polynomial equation relating microscopic cell counts to optical density (million cells $/ \mathrm{ml}=0.0525+\left(\mathrm{A}_{660} \times\right.$ $\left.20.255)+\left[\left(A_{660}\right)^{2} \times(28.366)\right]\right)$. Cell cultures grown with oleic acid or mixtures of oleic acid plus trans fatty acid gave an average of $48 \pm 4$ million cells $/ \mathrm{ml} / \mathrm{A}_{660}$.

\section{F. Cell isolation and lipid extraction}

KD 46 was grown on $\left[{ }^{3} \mathrm{H}\right]$ oleic acid in various combinations with $\left[1{ }^{14} \mathrm{C}\right]$ elaidic or trans-vaccenic acid. At various time points, $2.0 \mathrm{ml}$ of the cultures were removed and placed into $12 \mathrm{ml} \mathrm{screw} \mathrm{cap} \mathrm{tubes.} \mathrm{Cells} \mathrm{were} \mathrm{separated} \mathrm{from} \mathrm{the} \mathrm{culture} \mathrm{me-}$ dium by centrifugation and the medium collected for radioactivity measurement. The cell pellet was washed twice with $2.0 \mathrm{ml}$ of $0.15 \mathrm{M}$ sodium chloride with vigorous mixing and the sodium chloride washes collected for radioactivity measurement.

To the washed cell pellet $2.0 \mathrm{ml}$ of extraction solvent I [chloroform/methanol/ diethylether; $(1 / 1 / 1) ;(v / v)]$ was added; the tube was then capped and heated for 30 min at $70^{\circ} \mathrm{C}$ with intermittent shaking, cooled and the organic extract removed. The cell residue was again extracted as described above $\left(15 \mathrm{~min}\right.$ at $70^{\circ} \mathrm{C}$ ). Both extracts were combined and the solvent was removed in a stream of nitrogen. The cell residue was then treated with $2.0 \mathrm{ml}$ solvent II [ethanol/water/diethylether/pyridine $(15 / 15 / 5 / 1)(\mathrm{v} / \mathrm{v})](7)$ at $70^{\circ} \mathrm{C}$ for 30 minutes, and then washed once with $3 \mathrm{ml}$ chloroform-methanol (1: 1) (v/v) and once with $3 \mathrm{ml}$ chloroform. The cell residue was rinsed with $2.0 \mathrm{ml} 0.001 \mathrm{~N} \mathrm{HCl}$ and the aqueous phase transferred to the combined organic extracts. The total lipid extract was vigorously shaken and the aqueous phase separated from the organic phase. Aliquots from both the aqueous phase and the or: ganic phase were removed for measurement of radioactivity.

The use of both solvents ( $\mathrm{I}$ and II) together provided conditions under which the overall isotope recovery from medium, washes and cells was $87.0 \% \pm 12 \%$. Direct inter-esterification of the washed cell pellet with $\mathrm{BF}_{3}$ in methanol, followed by extraction of the methyl esters with petroleum ether yielded an overall isotope recovery of $\geqslant 97 \%$. This high recovery suggests that any isotope loss in our studies occurred mainly as a result of inefficient removal of the yeast cell lipids by the extraction sol. vents.

Values reported here were corrected by a proportionate reassignment of the unrecovered isotope to recovered cell lipid fractions. The total lipid extract was evapor: 
ated to dryness in a stream of nitrogen, redissolved in a minimum of chloroform/ methanol (1: 1) and applied to analytical silica gel $\mathrm{H}$ plate ( $(1.25 \mathrm{~mm}$ thickness). The thin layer plate was developed with the solvent system consisting of petroleum ether/diethyl ether/acetic acid $(40 / 60 / 1)(v / v)$. The approximi te mobilities for phospholipids, monoglyceride, 1,2-diglyceride, 1,3-diglyceride, free fatty acid and triglyceride were $0.0 ; 0.03,0.20 ; 0.28 ; 0.55$; and 0.79 respectively. The chromatogram was scanned with a radioisotope TLC scanner, the complete chroma ogram was divided into appropriate fract ons containing the major lipids and lipid-fiee bands. The fractions were scraped into liquid scintillation vials and counted.

\section{Results}

\section{A. Altered lipid contents with impaired growth}

Control cultures grown in the absence of nutrient unsaturated fatty acid generally underwent one cell doubling prior to cessation of growth. Supplementation with $25 \mu \mathrm{M}$ oleic acid resulted in a net cell yield of 30 million cells per ml culture (table 1). When either elaidic or trans-vaccenic acid was added in the presence of oleic acid, the cell yields were reduced to levels similar or less than those observed in the absence of any added nutrient unsaturated fatty acid. In the case of $26 \mu \mathrm{M}$ oleate plus $30 \mu \mathrm{M}$ trans-11-acid (Experiment C), the cell density after $24 \mathrm{hr}$ of growth was identical to that at the start of the experiment. This gave a negative net cell yield relative to the unsupplemented control culture. Although there was no appreciable increase in cell number, triglyceride increased during the 24 -hr period. Incorporation of $\left[{ }^{3} \mathrm{H}\right]$ oleic acid into total cellular lipids (in terms of nmoles per ml of culture) was lower for cultures supplemented with trans-fatty acids, but it was increased 1.5 to 2 -fold in the triglyceride fraction. To demonstrate the changes in lir:id synthesis in terms of cellular metabolic activities, we also expressed the esterified $\left[{ }^{3} \mathrm{H}\right]$-oleate in terms of attomoles/cell. In this manner, a 10 and 5 -fold increase occurred in the apparent concentrations of the triglycerides and diglycerides respectively, when trans-acids were present. Despite an apparent 42-fold increased intracellular concentration of $\left[{ }^{3} \mathrm{H}\right]$-oleic acid ( 1300 amoles/cell), oleate incorporation into phospholipids was reduced from 420 amoles/cell with oleate alone to 160 and 240 amoles/cell with 11 and 9-trans acids respectively. The increased synthesis of neutral lipids with a concomitant decrease in phospholipid synthesis suggested an inhibitory effect on phospholipid synthesis by the trans-acid or by some esterified product of the trans-acid.

The relationship between cell growth and oleate incorporation into lipids of normal cells is demonstrated in Figure 1A. During the first $2 \mathrm{hr}$ of growth with oleate as the sole nutrient fatty acid, the intracellular oleate increased to $7.5 \mathrm{nmoles} / \mathrm{ml}$ culture with a simultaneous rapid incorporation into phospholipids, reaching an optimum incorporation at $8 \mathrm{hr}$ of $21 \mathrm{nmoles} / \mathrm{ml}$ culture. Addition of increasing concentrations of trans-vaccenic acid to the medium from 10 to $20 \mu \mathrm{M}$ (at a constant oleate 
Table 1

Effect of 9 -trans and 11 -trans octadecenoic acids on the incotporation of oleate $(9$-cis) into cellular lipids.

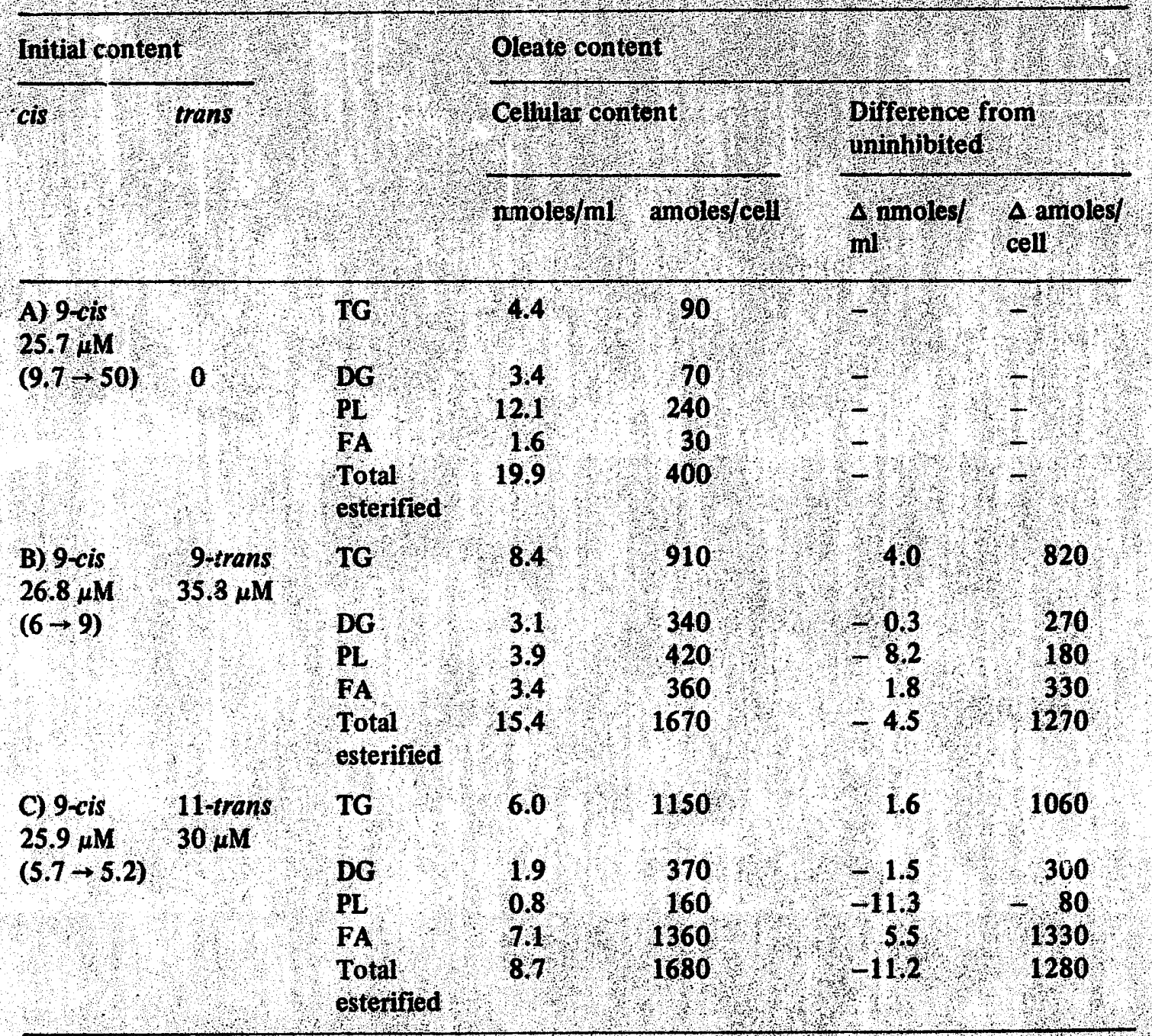

Cell cultures were grown for $24 \mathrm{hr}$ at $30^{\circ} \mathrm{C}$ in YEPD medium supplemented with A) $25.7 \mathrm{hM}$ 9,10 [ $\left.{ }^{3} \mathrm{H}\right]$-cis-octadecenoic acid, B) $26.8 \mu \mathrm{M} 910 \mathrm{I}^{3} \mathrm{H}$, cis-octadecenóic acid plus $35.8 \mu \mathrm{M} 9$ trans- $\left[1 .{ }^{14} \mathrm{C}\right]$-octadecenoic act and c) $\left.25.9 \mu \mathrm{N} / 9,10,1 \mathrm{H}\right] \mathrm{cis}$ octadecenoic acid plus $30 \mathrm{MM} 11$ trans-octadecenoic acid plus $30 \mathrm{~N}$. 11-trans-octadeceno c acid. The culfures initially contained 9.7; and $5.7 \times 10^{6}$ cens/mi, respectively, Control cullures grown in the absence of nutrient un saturated fatty acids produced maximum cell yields of $19.1,10.1$ and $9.9 \times 10^{6} \mathrm{cells} / \mathrm{m} / \mathrm{respec}$ tively. The values in parenthesis represent the change in cell content [milion cells/mi culture] over 24 hr of growth. Abbreviations used represent: TG = triglyceride; DG = diglyceride; $\mathrm{PL}=$ phospholipid; FA = free fatty acid.

concentration) decreased the oleate incorporated into the phospholipid fraction from 14 to 5.5 umoles/ml culture $(f i g, 3 \mathrm{~A}, \mathrm{~B})$ ). A similar inhibition in phospholipid synthesis was observed when trans-vaccenate $(20 \mu \mathrm{l})$ ) was replaced by claidate $(18 \mu \mathrm{M}$ ) (fig. 1B). In connection, with the early cessation of phospholipid gynthesis of trans-acid supplemented celis, the cellular unesterified fatty acid content dedined 


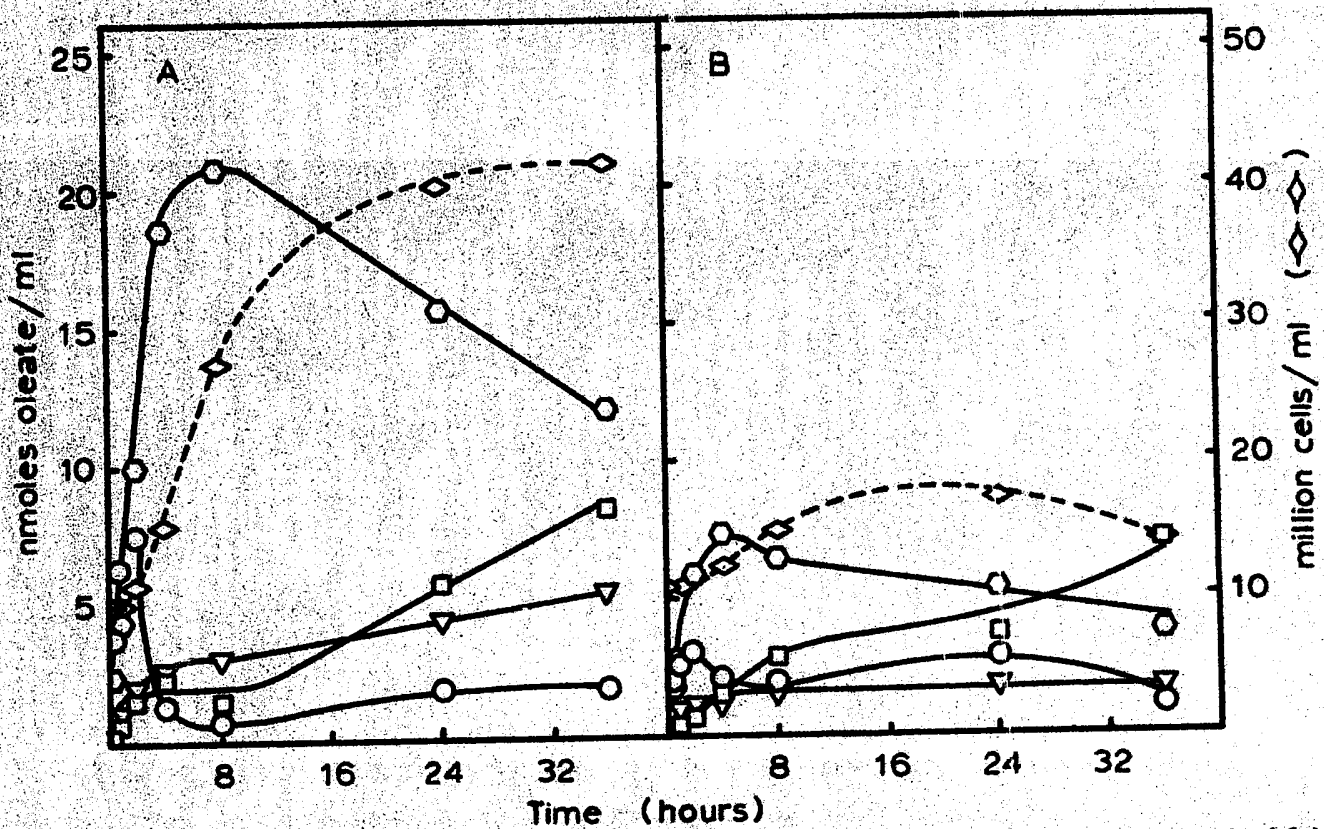

Fig. 1. Time course of oleate incorporation into cellular lipids of s. cerevisiae KD 46 in the absence or presence of 9-trans-octadecenoic acid. The culture was supplemented with (A) $34 \mu \mathrm{M}$ $\Delta 9,10$-cis-octadecenoic acid or (B) $17.8 \mu \mathrm{M} \Delta 9,10-\left[{ }^{3} \mathrm{H}\right]$-cis-octadecenoic acid plus $18.4 \mu \mathrm{M} \Delta 9$ trans-[1- $14 \mathrm{C}$-octadecenoic acid. Cell growth in $16.0 \mathrm{ml}$ YEPD medium at $30^{\circ} \mathrm{C}$ was monitored tubidometrically at $660 \mu \mathrm{M}$. At time points indicated $2.0 \mathrm{ml}$ aliquots were removed, cells were isolated, washed, cell lipids ex tracted and separated by thin layer chromatography as described in Methods. The symbols used are: 0 , free fatty acid; $\square$, triglyceride; $\nabla$, diglyceride; $\square$, phospholipids; $\diamond$, cells/ml culture.

only slowly compared to that in cells grown on oleate as the sole unsaturated fatty acid. Under these conditions, esterification of oleic acid (or oleic plus elaidic acid) was diverted into cellular triglycerides and continued at a fairly constant rate throughout the experiments (fig. 1A, 2A, 3B). In all instances, synthesis of cellular

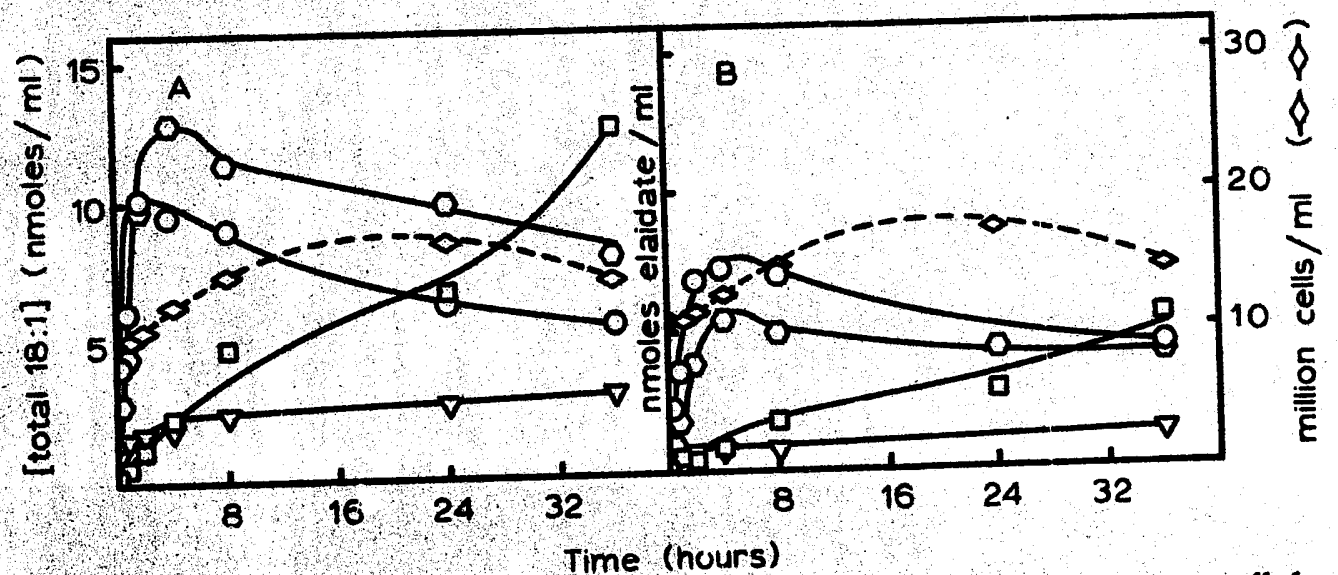

Fig 2. Effect of 9-trans-isomer on the time course of oleate incorporation into cellular lipids. (A) total octadecenoate (9-cis plus 9-trans); (B) 9-trans $-\left[1{ }^{14} \mathrm{C}\right]$-octadecenoate. Cultures (in YEPD mdeium at $30^{\circ} \mathrm{C}$ contained $17.8 \mu \mathrm{M} 9,10-\left[^{3} \mathrm{H}\right]$-cis-octadecenoic acid plus $18.4 \mu \mathrm{M}$ 9trans $\left[1^{14} \mathrm{C}\right]$-octadecenoic acid. Symbols are as in fig. 1 . 


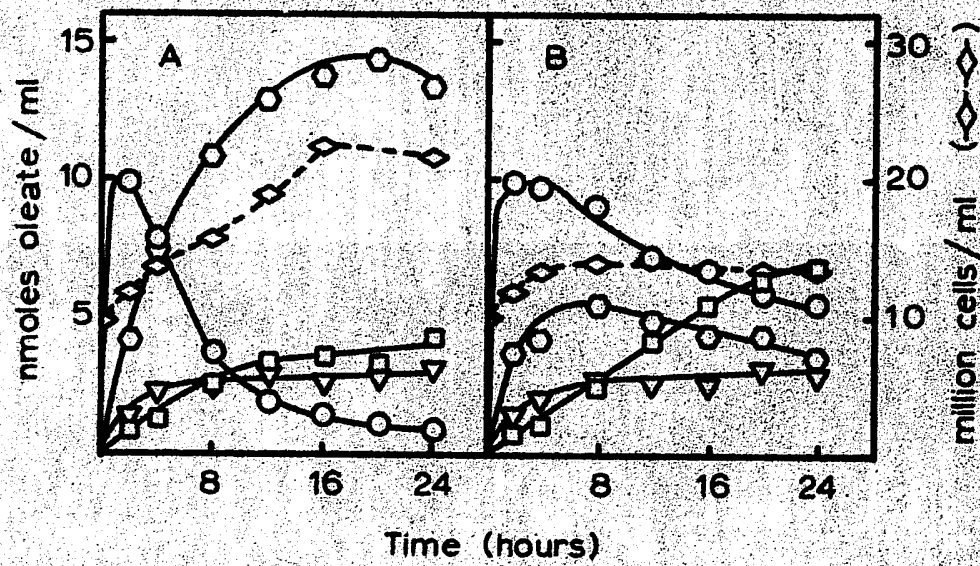

Fig. 3. Effect of 11-trans-octadecenoic acid on the time course of oleate (9-cis-octadecenoic acid) entry and incorporation to cellular lipids. Cultures were grown at $30^{\circ} \mathrm{C}$ in YEPD medium. (A) supplemented with $25.9 \mu \mathrm{M} 9,10-\left[{ }^{3} \mathrm{H}\right]$ cis-octadecenoic acid plus $10 \mathrm{MM} 11$ trans-octadecenoic acid. (B) supplemented with $26.6 \mathrm{\mu M} 9,10-\mathrm{r}^{3} \mathrm{H}$-cis-octadecenoic acid plus $20 \mathrm{\mu M}$ 11-trans-octadecenoic acid. Symbols are as in fig. 1.

diglycerides reached a steady state level after $4 \mathrm{hr}$ (ranging between $2-4 \mathrm{nmoles} / \mathrm{ml}$ culture) and remained constant thereafter. The data shown in fig. $3 \mathrm{~A}$ indicate that the conditions are probably just prior to those that would divert cellular lipid metabolism from phospholipid to triglyceride synthesis. The 2 -fold higher amount of trans-11 isomer (fig. 3B) produced a distinct shift in metabolism. Nevertheless, the rate of oleate esterification to phospholipids and the rate of cell division, as compared to normal cells (fig. 1A), appear to be impaired in both systems. The pattern of phospholipid synthesis and cell growth of either normal or inhibited cells indicates a close relationship between phospholipid synthesis and cell division, which appears not to exist for diglyceride and triglyceride synthesis.

\section{B. Alteration in synthetic paths with time}

To investigate the onset of the effect of elaidic acid on the formation of cellular lipids we initially exposed cells to elaidic acid and determined the rates of oleate esterification at various times of growth thereafter. In these studies corrections were made for isotope dilution by $\left[{ }^{3} \mathrm{H}\right]$ aleic acid remaining in the medium at the time of addition of the $\left[{ }^{14} \mathrm{C}\right]$-tracer, but not for that present inside the cells.

In normal cells, not exposed to elaidic acid, oleate rapidly entered the cells and was incorporated into phospholipids at a rate of about $7 \mathrm{nmoles} / \mathrm{ml}$ culture $/ \mathrm{hr}$ (fig. 4A). A similar initial rate of oleate entry and esterification to phospholipids for the first 10 minutes of incubation also occurred with elaidate-treated cells. This rate however could not be sustained ( $(\mathrm{g}, 4 \mathrm{~B}$ ) and progressively declined within one hour of incubation. Contrary to phospholipid synthesis, the rate of oleate incorporation into trigly ceride in elaidate-treated cells was stimulated about 2.5 fold (from 1.0 to 


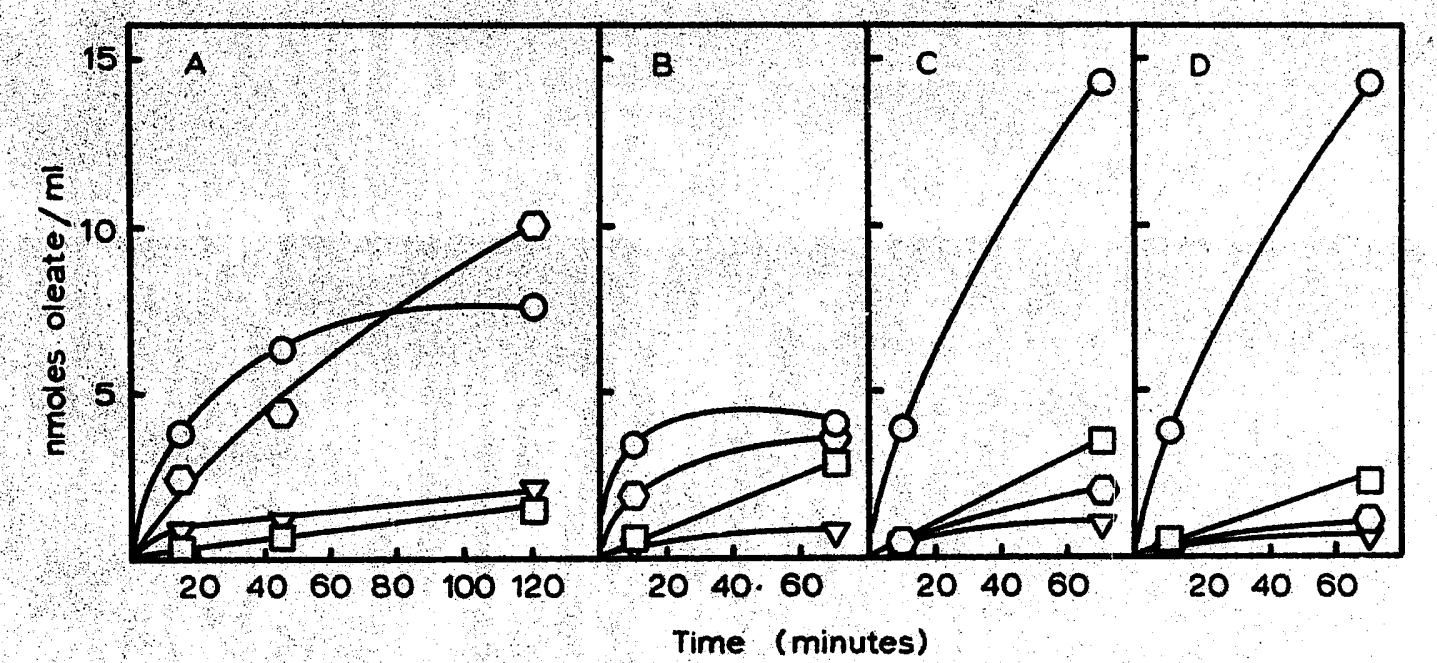

Fig. 4. Incorporation of oleate (9-cis) into cellular lipids of $S$. cerevisiae $\mathrm{KD} 46$ at various times after exposure to the 9-trans-isomer. Cultures at $30^{\circ} \mathrm{C}$ in YEPD medium (10 ml) contained (A) $34 \mu \mathrm{M} 9$-cis-isomer or (B, C, D) $20 \mu \mathrm{M} 9,10-\left[^{3} \mathrm{H}\right]$-cis-octadecenoic acid plus $20 \mu \mathrm{M}$ 9-trans-octa decenoic acid. For cultures containing the trans-isomer, additions of $9-c i s-\left[1-{ }^{14} \mathrm{C}\right]$-octadecenoic acid were made to give oleate concentrations of (B) $20.7 \mu M$ at $0 \mathrm{hr}$;(C) $26.0 \mu M$ at $9 \mathrm{hr}$; and (D) $23.8 \mu \mathrm{M}$ after $17 \mathrm{hr}$ of growth. Aliquots of $4.0 \mathrm{ml}$ were removed immediately and also 60 min after the addition of the $9-$ cis- $\left[1{ }^{14} \mathrm{C}\right]$-octadecenoic acid pulse. Cells were rapidly isolated, washed, the cell lipids extracted and separated by thin layer chromatography. Symbols are as in fig. 1.

$2.5 \mathrm{nmoles} / \mathrm{ml}$ culture $/ \mathrm{hr}$ ) despite the lower apparent intracellular non-esterified oleate concentration.

After 9 and $17 \mathrm{hr}$ of exposure to the trans-isomer (fig. 4C, D), the cells ability to esterify oleic acid into triglycerides proceeded unchanged at rates of 2 to 3 nmoles/ $\mathrm{ml} \mathrm{culture} / \mathrm{hr}$, in comparison to $1 \mathrm{nmole} / \mathrm{ml}$ culture/hr in normal cells. The rate of oleate incorporation into phospholipids, however, declined further from 2 to 1 $\mathrm{nmoles} / \mathrm{ml}$ culture/hr, despite high intracellular concentrations of free oleate (13 nmoles $/ \mathrm{ml}$ culture as compared to $7 \mathrm{nmoles} / \mathrm{ml}$ culture in normal cells after $1 \mathrm{hr}$ ). In all instances oleate incorporation into diglycerides reached a steady state level of about $1 / 3$ to $1 / 2$ that of normal cells after $1 \mathrm{hr}$.

\section{Discussion}

The biosynthesis of phospholipids in S. cerevisiae appears to follow patliways recognized for other eukaryotic cells. Glycerol-3-phosphate forms phosphatidate which then can form either diglycerides or CDP-diglycerides [8]. The diglycerides, in turn, can form either triglycerides or phosphatidylcholine and ethanolamine derivatives. Considerable interest in these two "branch points" of lipid metabolism is uncouraged by the concept that triglycerides (or fats) are of less utility than phosphoglycerides to dynamic cells and their accumulation often reflects undesired conditions. We share 
the interest in how a cell controls the flow of metabolites to these classes of lipids. Studies of CDP-choline levels in choline deficient rats [9] and enzyme activities in different states [10] have still not provided a firm interpretation of how the eukaryo. tic cell can regulate its levels of fat and phospholipid. The finding of transient accumulation of triglycerides in rat heart following ingestion of rapeseed oils of 1 igh erucic acid content $[11,12]$ represents another stimulus to understand the control of these metabolic branch points. In this instance, some selective action of erucic icid upon lipid metabolism appears likely since corresponding dietary levels of other fats do not produce the effect.

The findings of Vandenhoff et al. [4], confirmed in this report, indicate that certain positional isomers of trans octadecenoate can promote triglyceride formation in $S$ cerevisiae. The effect was dependent upon the concentration of acid and selective in that not all fatty acids gave this effect. Recognition that a variety of nutrient acids can affect lipid metabolism provided impetus for our study of the shift in biosynthetic pathways.

\section{A. Triglyceride accumulation in yeast}

Greater amounts of triglyceride (4-fold) accompanied by 2 -fold lower levels of phospholipid per $\mathrm{g}$ (dry wt.) were reported when S. carlsbergensis 4228 was grown in the absence of supplementary inositol [13]. While examining this phenomenon, Paltauf and Jchiston $[14,15]$ observed that triglyceride accumulation occurred in deficient cells throughout the growth phase and was much greater in cells grown with glucose. Thi decreased growth rate and increased triglyceride content were not, however, simply related to omission of inositol from the culture. Cells grown without supplemental inositol but with lactate as a carbon source showed growth rate, lipid content and phosphatidylinositol content similar to that of supplemented cells. Apparently glucose interferes with adequate inositol metabolism in a way that prevents adequate growth. It is difficult to discern whether the intracellular signals that cause the decreased growth rate also increase trigly ceride accumulation or whether triglycerides accumulate solely because of the decreased growth rate. Hunter and Rose [16] indicated that decreased growth temperature can also produce increased lipid content per cell accompanied by a decreased growth rate. Slightly decreased phospholipid content and somewhat increased trigly ceride levels per cell could also be obtained when growth rates were reduced by limiting glucose levels. Thus, an inverse relationship between growth rate and triglyceride content is indicated.

When diploid S. cerevisiae (DCL 740) were maintained in sporulating medium (KCl-acetate), they developed (after $24 \mathrm{hr}$ ) visible asci, and increases of 2.7 -fold in triglyceride, 3 -fold in diglyceride, 2.7 fold in phospholipid and 1.3-fold in unesterified fatty acid per cell [17]. After 120 hr of exposure to the sporulation medium, no further change in phospholipids, digly cerides and free fatty acid were evident, but triglyceride further increased an additional 3.3 -fold beyond that at $24 \mathrm{hr}$. Two phases of lipid synthesis were described for sporulating diploid cells [18]. Phase I occurred 
during the period of cell growth $(0-15 \mathrm{hr})$ when most phospholipid was synthesized. The content of triglyc,ride (and sterol plus sterol esters) also increased greatly during this time, as well as in the later Phase II $(20-26 \mathrm{hr})$ when asci were formed. Since non-sporulating (haploid) cells exhibited only the Phase I phenomenon, the specialized channeling of fatty ycids only into triglyceride at the later time seems triggered by or dependent upon the intracellular signals accompanying ascus production. Interestingly, the earlier accimulation of triglyceride in haploid and diploid cells in sporulation medium ( $2 \%$ potassium acetate) occurs while phospholipids and cellular membranes are also increasing and accumulation does not appeaf to be a result of cell death.

\section{B. Lipid changes in cultured nammalian cells}

King et al. [19] reported that neutral lipid, phospholipid and cholesterol accumulated in eukaryotic L-strain fibroblasts and in Ehrlich ascites cells during retardation of cell division and protein synthesis. Furthermore, the lipid-laden cells apparently underwent a progressive decrease in lipid content when stimulated to active division. Mackenzie et al. [20] noted that triglyceride accumulation in L-cells and rabbit liver cells was much greater with rabbit serum than with horse serum. This lipogenic activity was attributed to non-esterified fatty acids bound to serum albumin in the medium [21]. The source of lipid in such cultured cells is apparently the free fatty acid bound to albumin in the serum added to the medium [22-24]. Triglycerides are also utilized by cultured cells $[25,26]$. Although this can occur by means of lipase action to produce the readily incorpcrated free fatty acids [22], Bailey et al. [27] reported that uptake by $L$-cells involved the intact triglyceride molecule. The degree of cellular lipid accumulation or steatosis seems to reflect the concentration on nonesterified unbound fatty acid anion to which the cell is exposed $[28,29]$. Thus, fat accumulation can be decreased by use of (a) low concentrations of free fatty acid in the medium [30]; (b) lipid-depleted serim proteins [31,32] or (c) esterified forms of fatty acid $[26,33,34]$.

Moskowitz [31] noted that the microssopically assigned degrees of steatosis (sudanophilia) were roughly proportional to the ratio of triglyceride to phospholipid in the cells, and were detectable from values of 0.5 to 2 or greater. Usually, the triglyceride content is much less than the relatively constant content of polar lipids (equal to $0.154 \times$ protein) in mammalian cells [20]. Although the triglyceride levels varied five to ten-fold, the highest content of accumulated triglyceride was comparable to that for phospholipids. In our present report, using the mutant of $S$. cerevisiae (KD 46) that requires unsaturated fatty acid, we could define in a more detailed manner the alterations in lipid metabolism that lead to the accumulation of triglycerides. Athough triglyceride synthesis is a normal metabolic processs in yeast lipid metabolism (e.g, when cultured with oleate), it contributed generally only a minor portion of the total esterified cellular lipid content ( $1 / 3$ or less). Under conditions when cells were cultured in a high concentration of oleate, the triglyceride content 
was always less than that of phosphoglycerides [3]. Thus cellulat accumulation of triglycerides appeared to require an additional stimulus ot ther than an extracellular excess of nutrient fatty acid. Both, elaidic and vaccenic acid, as tested in this studf; provided conditions that stimulated this process. Our data indicate that an alteration in metabolic paths was rapidly induced upon exposing cells to trans-fatty acids. This was reflected by the progressively decreasing rate in phospholipid synthesis, followed by a stimulation in triglyceride production. This phenomenon was clearly dependent upon the concentration of trans-fatty acid. Exposed cells were capable of completing orie round of cell division, but simultaneously with the cessation in net phospholipid synthesis, the cells failed to divide. As a consequence of inhibition of phospholipid synthesis, trigly ceride formation seems the only alternate route for the utiliza. tion of esterified intracellular fatty acids. Triglyceride accumulation in yeast therefore may be secondary in nature, preceded by some pleiotropic cellular event that altered the activity of the "branch point" enzymes.

Selective aspects - Different nonesterified acids $(16: 0,18: 0,18: 1,18: 2)$ seem to be taken up and metabolized by Ehrlich ascites cells in a qualitatively similar fashion and at roughly comparable rates [35]. Stearate and linoleate entered somewhat faster into phospholipids than trigly cerides whereas the reverse was true for oleate. Thus, no evidence for appreciably different effects of different acids was obtained. Although no data on cellular lipid contents were provided, another study of the degree to which acyl chain structure influences cells indicated that the 3 -and 17-isomers of sixteen different positional isomers of cis-octadecenoate inhibited growth of MK cells [36]. The data also indicated a possible internnediate ability of the 4 and 16-isomer to support growth, whereas all other isomers tested were as effective as oleate (cis-9). Such a pattern of selectivity differs from that seen for Leptospira interrogans [37] and $E$. coli [38] and S. cerepisiae [39].

Vandenhoff et al. [4] demonstrated that $S$. cerevisiae incorporated trans-octadecenoate isomers into cellular phospholipid to a similar mole \% content. However, all positional isomers except the 8 inhibited growth in the presence of oleate. This inhibitory action was selective and different in magnitude for different isomers. The phospholipid content per cell increased somewhat when cell division was inhibited, whereas the content of neutral glycerides increased up to 100 -fold. The doubled amount of phospholipid described for the non-growing cultures [4] may indicate that cell division failed at a stage in the cell cycle when enough membrane phospholipid was available for two cells. Perhaps, inability to proceed further toward division provides a signal that stops formation of phospholipid. Then, if none of the customary membrane phospholipids can be formed, but the early part of the biosynthetic pathway for glycerolipid is still operating at an undiminished rate, accumulation of triglycerides seems an inevitability.

The concept of reciprocal interdependency (or "stringency") among systems that form cellular macromolecules encompasses vital control features. Thus, lack of RNA can prevent protein synthesis, but also an inadequate amino acid supply can decrease synthesis of RNA (and DNA) in "stringent" cells [40]. This control apparently ex. 
tends also to phospholipid synthesis $[41,42,43]$ and there is a possibility that lack of adequate phospholipid synthesis can prevent synthesis of protein, RNA, and DNA $[44,45,46]$. Such interdependencies provide a complex cycle of pleiotropic phenomena in which phospholipid biosynthesis and composition can play a role. Although the content of phospholipid per cell in the prokaryotic E, coli seems to be constant [47], we have observed a range for $S$, cerevisiae [3]. This result may indicate that a more varied, complex combination of lipids and proteins can be produced in eukaryotic cells. It may not be appropriate to assume a constant phospholipid content in the membrane of these cells in the manner predicted by a unit membrane assembly concept. Rather, we may have to accept multiple, independent insertion and removal of phospholipids (as well as proteins) in some mosaic assembly. If so, the term "membrane" is describing an ill-defined chemical entity of a complex mixture of components in varying proportions - much as the term "lecithin" was prior to the time when Erich Baer initiated his definitive, disciplined studies which let us exanine more clearly the individual component molecular species of the lecithins. We look forward to applying the lessons of the past in approaching the complex pleiotropic aspects of membranes that seem due to their mixtures of phospholipids.

\section{Acknowledgments}

This work was supported in part by a grant (AM 05310) from the United States Public Health Service and a NIH Post-doctoral Research Fellowship (1-F-326M0534401). We thank Jean A. Craig and Roger W. Sacks for technical assistance.

\section{References}

[1] A treatise on the chemical constitution of the brain by J.L.W. Thudichum, with a new historical introduction by D.L. Drabkim, Archon Books, Hamden, Conneticut (1962)

[2] E. Baer, J. Am. Oil. Chem. Soc. 42 (1965) 257

[3] B. Holub and W.E.M. Lands, Can. J. Biochem. 53 (1975) 1262

[4] G. Vandenhoff, F.D. Gunstone, J. Barve, and W.E.M. Lands, J. Biol. Chem. 250 (1975) 8720

[5] L.D. Metcalfe and A.A. Schmitz, Anal. Chem. 33 (1961) 363

[6] A.D. Keith, M.R. Resnick, and A.B. Haley, J. Bacteriol 98 (1969) 415

[7] W.W. Angus and R.L. Lester, Arch. Biochem. Biophys. 151 (1972) 483

[8] M.R. Steiner and R.L. Lester, Biochim. Biophys. Acta 260 (1972) 222

[9] G.F. Wilgram, C.F. Holoway, and E.P. Kennedy, J. Biol. Chem. 235 (1960) 37

[10] D.L. Young and F. Lynen, J. Biol. Chem. 244 (1969) 377

[11] A.M. Abdelatif and R.O. Vles, Nutr. Metabol 12 (1970) 285

[12] J.L. Beare-Rogers, E.A. Nera, and H.A. Heggtveit, Can. Inst. Food Technol. J. 4 (1971) 120

[13] T. Shafai and L.M. Lewin, Biochim. Biophys. Acta 152 (1968) 790

[14] F. Paltauf and J.M. Johnston, Biochim. Biophys. Acta 218 (1970) 424

[15] J.M. Johnston and F. Paltauf, Biochim. Biophys. Acta 218 (1970) 431

[16] K. Hunter and A.H. Rose, Biochim. Biophys. Acta 260 (1972) 639 
[17] R.F. Ilingworth, A.H. Rose and A. Beckett, J Bacteriol 113 (1973) 373

[18] S.A. Henry and H.O. Halvorson, J. Bacterid $114(1973) 1158$

[19] D.W. King, E, L Socolow, and K.G. Bensch, J Biophys. Biochen. Gytol 5 (1959) 421

[20] C.G. Mackenzie, J.B. Mackenzie, and O.K. Reiss, Exp. Cell Res, 3601964533

[21] C.G. Mackenzie, J.B, Mackenzie, OK, Reiss, and I. A. Wisneski, J. Lipid, Res 11 (1970) 571

[22] B.V. Howard and D, Kritcheviky, Biochim, Biophys, A ta 187 (1969) 293

[23] R.P. Geyer, A. Bennet, and A. Rohr, I. Upld Res. $3(1904) 80$.

[24] J.M. Bailey, Biochin. Biophys. Acte 125 (1966) 226

[25] J.M. Bailey, G,O. Gey and M.K. Gey, Roc, Soc. Exp Biol Med, 100 (1959) 686

[26] R.P. Geyer, Lipid Metabolism in Thsie Cuiture Cells. Ed. G.H. Rothblat and D. Kritchersky (1967) The Wistar Institute Press

[27] J.M. Bailey, B.V. Howard, and S. F, Tilmann J Biol. Chem, 248 (1973) 1240

[28] A.A. Spector, D. Steinberg, and A. Tanaka, J. Biol. Chem. 240 (1965) 1032

[29] M.S. Moskowitz, Lipid Metabolism in Tissue Culture Cells, Ed, GHI Rothblat and D. Kritchevsky (1967) The Wistar Institute Press

[30] H.M. Jenkin and L.E. Anderson, Exp. Cell Res, $59(1970) 6$

[31] K.A. Ferguson, M. Glaser, W.H. Bayer, and P. R. Vagelos, Biochem. 14 (1975) 146

[32] A.F. Horwitz, M.E. Hatten, and M.M. Burget, Proc. Nat. Acad. Sci. USA 71 (1974) 3115

[33] B.J. Wisnieski, R.A. Williams, and C,F. Fox, Proc. Nat. Acad. Sci. USA 70 (1973) 3669

[34] R.E. Williams, B.J. Wisnieski, H.G. Rittenhouse, and C.F. Fox, Biochem. 13 (1974) 1969

[35] A.A. Spector and D. Steinberg, Canc. Res. 27 (1967) 1587

[36] H.M. Jenkin, L.E. Anderson, R.T. Holman, 1. A. Ismail, and F D. Gunstone, Exp. Cell Res. $59(1970) 1$

[37] H.M. Jenkin, L.E. Anderson, R.T. Holman, I.A. Ismail, and F.D. Gunstone, J. Bacteriol. 98 (1969) 1026

[38] E.D. Barber and W.E.M. Lands (unpublished results)

[39] R.W. Walenga and W.E.M. Lands, J. Biol. Chem. 250 (1975) 9121

[40] M.K. Sands and R. B. Roberts, J. Bacteriol. 63 (1952) 505

[41] Y. Sokawa, E. Nakao-Sato, and Y. Kaziro, Biochim Biophys. Acta 199 (1970) 256

[42] N.G. Golden and G.L. Powell, J. Biol, Chem. 247 (1972) 6651

[43] W.D. Nunn and J.E. Cronan, J. Biol. Chem. 249 (1974) 3994

[44] M. Glaser, W.H. Bayer, R.M. Bell, and P.R. Vagelos, Proc. Nat. Acad. Sci. USA 70 (1973) 385

[45] J.A. Fralick and K.G. Lark, J. Mol. Biol 80 (1973) 459

[46] R.W. Walenga and W.E.M. Lands, J. Biol. Chem, 250 (1975) 9130

[47] J.B. Ohlrogge, Ph.D. Thesis, University of Michigan, (1976) 